\title{
Prevalence of and reasons for domestic violence among women from low socioeconomic communities of Karachi
}

T.S. Ali ${ }^{1,2}$ and I. Bustamante-Gavino ${ }^{2}$

$$
\begin{aligned}
& \text { انثشار العنف الأسري وأسبابه بين النساء في الجتمعات ذات المستوى الاجتماعي والاقتصادي } \\
& \text { المنخفض في كراتشي التئي }
\end{aligned}
$$

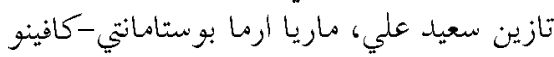

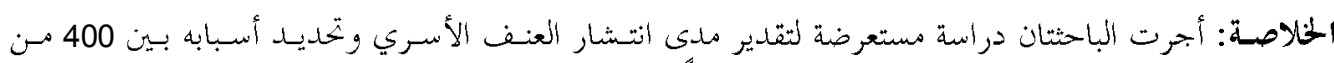

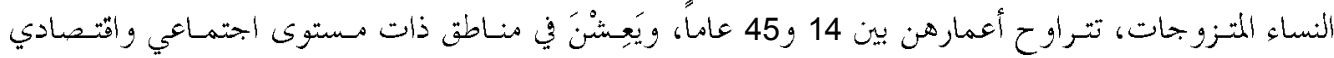

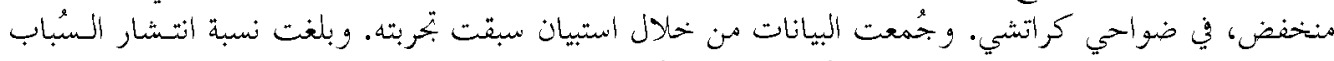

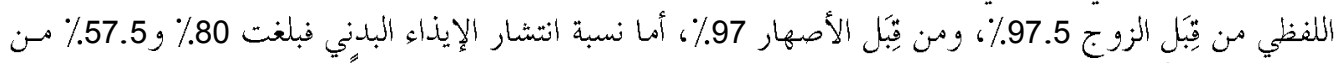

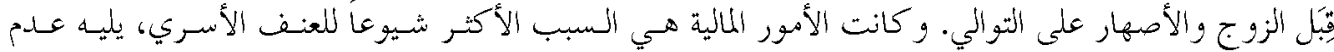

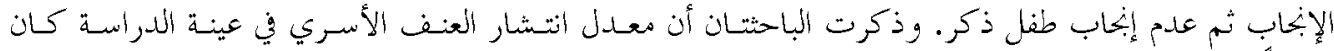

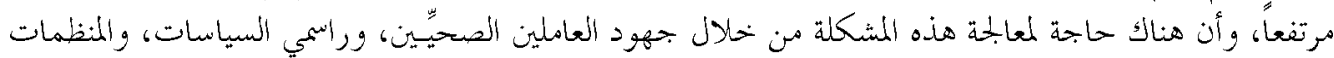

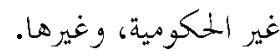

ABSTRACT We conducted a cross-sectional study to estimate the prevalence of domestic violence and identify the reasons for it among 400 married women aged 15-45 years in low socioeconomic areas in urban Karachi. Data were collected with a pretested questionnaire. The prevalence of verbal abuse was $97.5 \%$ by the husband and $97.0 \%$ by the in-laws; the prevalence of physical abuse was $80.0 \%$ and $57.5 \%$ by the husband and in-laws respectively. Financial issues were the commonest reason for domestic violence followed by infertility and not having a son. The prevalence of domestic violence in our sample of women is high. There is a need to address this problem with efforts from health workers, policy-makers, nongovernmental organizations and others.

Prévalence et causes de la violence domestique chez les femmes des milieux défavorisés de Karachi

RÉSUMÉ II a été procédé à une étude transversale ayant pour objectif l'évaluation de la prévalence de la violence domestique et de ses causes chez 400 femmes mariées âgées de 15 à 45 ans résidant dans les secteurs défavorisés de la zone urbaine de Karachi. Les données ont été collectées par le biais d'un questionnaire prétesté. La prévalence des violences verbales émanant respectivement du conjoint et de la belle-famille était de $97,5 \%$ et $97,0 \%$, tandis que celle des violences physiques s'élevait respectivement à $80,0 \%$ et $57,5 \%$. Les problèmes financiers arrivent en tête des causes de violence domestique, suivis par la stérilité et l'absence de descendance mâle. Dans notre échantillon de femmes, la prévalence de la violence domestique est élevée. Les personnels de santé, les responsables de l'élaboration des politiques, les organisations non gouvernementales et autres parties prenantes se doivent de conjuguer leurs efforts pour venir à bout de ce problème.

${ }^{1}$ Department of Community Health Sciences; ${ }^{2}$ School of Nursing, The Aga Khan University, Karachi, Pakistan (Correspondence to T.S. Ali: tazeen.ali@aku.edu).

المجلة الصحية لشرق المتوسط، منظمة الصحة العالمية، المجلد الثالث عشر، العدد Y، V... 


\section{Introduction}

Violence against women in developing countries is emerging as a growing concern for public health practitioners as it is well known that women are vulnerable to many forms of violence, and domestic violence represents the commonest form [1]. Domestic violence, or intimate partner violence (IPV), is defined by the American Medical Association as a pattern of physical, sexual and/or psychological abuse by a person with whom the victim has had an intimate relationship [2]. The World Health Organization (WHO) defines domestic violence as any act of "gender-based violence that results in, or is likely to result in, physical, sexual or mental harm or suffering to women, including threats of such acts, coercion or arbitrary deprivation of liberty, whether occurring in public or in private life." [3]. Domestic violence is an important cause of morbidity and mortality for women in every country where these associations have been studied [3]. In a literature review of population-based studies, Krug et al. found that $10 \%-69 \%$ of women reported that they had experienced physical abuse from a male partner [4]. There have been numerous studies in other communities in which women have reported experiencing domestic violence: $34 \%(n=6566)$ in an Egyptian study [5], 17\% in Canada [6], $16.4 \%$ in Haiti [7]. The reported reasons for abuse included non-compliance with female contraception, talking to strangers, jealousy; abuse has also been found to be associated with low income [5-8].

There are many forms of violence against women. These includes psychological (e.g. controlling behaviour, economic abuse, social isolation), physical and sexual abuse [1,9-11]. Physical violence can often result in multiple injuries and may lead to chronic conditions [12-14], while emotional abuse can have severe long-term effects [15].

In developing countries, women are more susceptible to domestic violence. For example, one study in Karachi in 2000 reported that all husbands surveyed admitted that they shouted at their wife, even when she was pregnant [16]; $32.8 \%$ admitted to having slapped their wives and $77.1 \%$ admitted to having engaged in non-consensual sex with their wives. Another study conducted in Karachi in 1999 reported that $34 \%$ of the women had been physically abused by their husbands and $15 \%$ had been abused even while pregnant. As a result, $72 \%$ of physically abused women were anxious/depressed [17]. Another study in 2005 on 176 married men showed that 94.9\% had ever used verbal abuse during their marital life and $49.4 \%$ had used physical abuse [18].

According to our recent study, it is not only the husband but also the in-laws who commit violence against women [19]. In Pakistan a joint or extended family system is the common practice where the husband and his wife live with his parents, sisters and brothers in one household. The wife is placed in a submissive position where she faces harassment from the whole family $[19,20]$.

The situation of domestic violence against women in Pakistan is far from clear but what is clear is that it is an issue and not much is being done to prevent it either by the government or nongovernmental organizations (NGOs). To be able to address the issue properly it is important to have baseline data about its prevalence and reasons behind violence against women [21]. Although some studies have been conducted in Pakistan, none has been entirely community based. Therefore we conducted a community-based study in a low socio- 
economic area with the following research objectives.

- To estimate the prevalence of domestic violence among a selected sample of women from low socioeconomic communities in Karachi, Pakistan.

- To identify the reasons for domestic violence among the women.

\section{Methods}

\section{Setting}

This was a cross-sectional descriptive study conducted from March to August 2003 in 5 low socioeconomic communities where populations of mixed ethnicity live: Korangi, Sohrab Goath, Orangi town, Mohajir camp and Layree. The inhabitants were the Mohajir (people who migrated from India at the time of partition), and urban migrants from Punjab (Punjabi) and Balouchistan (Baluchi). There are 3 types of dwelling: pucca which have cement walls, floors and roofs; katcha-pucca which have cement walls with roofs of asbestos/tin/wood; and kutcha which have walls and floor made of mud/tin/wood and roof made of asbestos/ tin. Public utilities, such as water, electricity and health care centres, are very limited in these areas. The 5 communities were selected based on the presence of a household surveillance system. At Korangi, Orangi town and Mohajir camp a national health workers programme is present working for maternal and child heath. At Sohrab Goth there was no such programme present. At Layree the Layree Community Development Project is doing developmental work.

\section{Study sample}

Sample size was calculated to assess the prevalence of violence against women of low socioeconomic areas in Karachi, Pakistan. The proportion of urban women experiencing violence was estimated at approximately 30\% [17]. Using Epi-Info for sample size calculation at the $95 \%$ confidence level with $5 \%$ error, sample size was estimated as 333 . To be able to capture variability of the reasons for violence identified in our study we finally enrolled 400 currently married women using purposive sampling. The participants were identified by community health workers of the programmes and projects present in the selected communities based on the following inclusion criteria.

- Informed consent to participate in this study given

- Resident of the community for more than 3 years

- Married

- Age between 15 and 45 years (reproductive age)

- Having at least 2 children.

- Registered for at least 2 years with the community health worker of the NGO or the national health programme of the government of Pakistan.

\section{Data collection}

The data collection instrument (questionnaire) was based on the main objectives of the study. Five focus group discussions (FGD) were held with currently married women in the selected communities. Data gathered from the FGD were used to develop the questionnaire. The questionnaire was originally developed in English and then translated into Urdu. Two rounds of pre-testing were run. Sociodemographic data of the participants were collected, including age of respondent/husband, age at marriage, duration of marriage, number of pregnancies, occupation (respondent and husband), education (respondent and husband), monthly household income, type of house and ownership of the house. Using

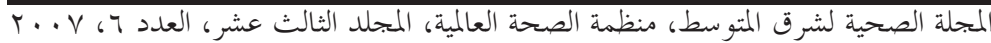


a closed-ended pre-coded questionnaire, information was also collected on verbal and physical abuse experienced by the respondent from the husband and/or in-laws. The reasons for violence were also elicited from the respondents with closed-ended questions.

The data were collected by 5 interviewers who were selected by the investigators, 1 for each study site. All the interviewers held masters degrees in Sociology, had taken some health-related training and had at least 2 years of data collection experience. All spoke Urdu and at least 1 other regional language. The interviewers were given 4 days of theoretical and practical training including explanation of the study objectives, sampling strategy, communication skills, questioning techniques, ethical considerations and completing the questionnaire. The training sessions included demonstration of communication skills, role-playing, lectures and case studies. Each data collector had to demonstrate their acquired skills until their performance was found to be satisfactory. Field supervisors, who were also sociologists with 10 years of field supervision, were involved in the training and conducted the qualitative work to develop the questionnaire.

The interviews were conducted during the day at the homes of the women, when the husbands were not around. The families were already comfortable with the health workers so it was not difficult to come into the house and collect data in private. Nonetheless, the data were collected with other information, to avoid any problems for the women. The women gave verbal consent easily and they were open in their answers.

The field supervisor was responsible for checking the data quality. The questionnaires were edited by the field supervisor on a daily basis both in the field and in the office. Incomplete questionnaires were returned to the interviewers to complete by revisiting the women in their homes. Surprise reinterviews were done by either the principal investigator or the co-investigator so as to recheck various variables of the questionnaire.

\section{Definitions}

The definition of domestic violence was developed from the literature review prior to the study.

- Conceptual definition (domestic violence): a pattern of physical, sexual, and psychological abuse by a person with whom the victim has had an intimate relationship [2].

- Operational definitions (domestic violence): violence as perceived by the women under study.

The following forms were seen as types of violence.

- Verbal violence (conflict): taunting, blaming, criticizing and shouting.

- Physical violence: beating, pushing, shoving, using any means such as hands, legs, sticks.

- Emotional violence: feeling anxious, depressed or upset due to conflicts with husband and/or in-laws.

\section{Ethical considerations}

The Ethics Review Committee of our institution approved the study. Before data collection, verbal informed consent was taken from all the women and they were assured that all the information would be kept confidential. There were 30 women who refused to participate and were replaced by women residing in the next neighbourhood who fulfilled the criteria.

\section{Data management}

Data were double entered into Epi-Info, version 6 . For analysis, the data were trans- 
ferred in to SPSS, version 10. Descriptive statistics were computed at The Aga Khan University by the principal investigator.

\section{Results}

\section{Sociodemographic characteristics}

The mean age of the women was 29.0 [standard deviation (SD) 4.6] years (range 19-39 years). The mean duration of marriage was 10.5 (SD 5.0) years and age at the time of marriage was 18.8 (SD 3.3) years. A total of 1661 pregnancies were reported by the 400 women with a mean of 4.1 (SD 1.7) pregnancies. Of the 400 women, $33.8 \%$ were illiterate and $25.5 \%$ of the husbands were illiterate. Only $24.0 \%$ of the women were employed, whereas the majority $(94.7 \%)$ of the husbands were employed. Most of the women lived in katcha pucca dwellings; only $69 \%$ owned their homes (Table 1).

\section{Prevalence of domestic violence}

The majority of women $(97.5 \%)$ reported that they had experienced verbal abuse (conflict) from their husbands and $97.0 \%$ experienced such abuse from their in-laws. As regards physical violence, $80.0 \%$ reported receiving beatings by their husbands and $57.5 \%$ experienced such violence from their in-laws. The majority of women reported feeling stressed by the conflict with their husbands (98.5\% of the women) and with their in-laws (97.3\%).

\section{Reasons for conflicts with husband and in-laws}

The main reasons for conflicts with husbands were reported as: financial causes $(65.0 \%)$, infertility $(33.3 \%)$, not having a son $(32.0 \%)$, husband beating or hitting the children $(21.3 \%)$ and husband being addicted to drugs (15.8\%) (Table 2).

The main reasons for conflicts with in-laws were reported as: household chores
Table 1 Sociodemographic characteristics of the $\mathbf{4 0 0}$ women in urban Karachi

\begin{tabular}{lc}
\hline Characteristic & Mean (SD) \\
\hline Respondent's age (years) & $29.0(4.6)$ \\
Duration of marriage (years) & $10.5(5.0)$ \\
Age at marriage (years) & $18.8(3.3)$ \\
Number of pregnancies & $4.1(1.7)$ \\
Monthly income of household & \\
$\quad$ in Pakistani rupees & \\
& $4000(3777)$ \\
& No. $\%$ \\
& $(\boldsymbol{n}=\mathbf{4 0 0 )}$
\end{tabular}

Years of schooling of respondent

$\begin{array}{lrr}\text { None, illiterate } & 135 & 33.8 \\ 1-5 & 77 & 19.3 \\ 6-10 & 132 & 33.0 \\ 11-14 & 48 & 12.0 \\ \text { University } & 8 & 2.0\end{array}$

Years of schooling of

respondent's husband

None, illiterate $\quad 102 \quad 25.5$

$1-5 \quad 52 \quad 13.0$

6-10 $165 \quad 41.3$

11-14 $60 \quad 15.0$

University $21 \quad 5.3$

Occupation of respondent

Housewife $\quad 304 \quad 76.0$

Employed outside the home $\quad 96 \quad 24.0$

Occupation of respondent's

husband

Unemployed $\quad 21 \quad 5.3$

$\begin{array}{lll}\text { Employed } & 379 & 94.7\end{array}$

Type of dwelling ${ }^{b}$

$\begin{array}{lll}\text { Katcha } & 18 & 4.5\end{array}$

$\begin{array}{lll}\text { Pucca } & 33 & 8.3\end{array}$

$\begin{array}{lll}\text { Katcha pucca } & 349 \quad 87.3\end{array}$

Owned the house

$\begin{array}{lll}\text { Yes } & 276 & 69.0\end{array}$

No, pay rent for it $\quad 120 \quad 30.0$

\begin{tabular}{lll} 
Provided by employer & 4 & 1.0 \\
\hline
\end{tabular}

aUS\$1 = 60 Pakistani rupees at the time of the study.

${ }^{b}$ Pucca have cement walls, floors and roofs;

katcha-pucca have cement walls with roofs of

asbestos/tin/wood; kutcha have mud/tin/wood walls

and floors with roofs of tin/asbestos.

$S D=$ standard deviation

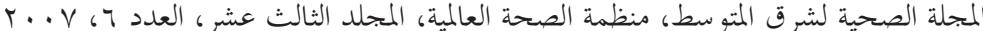




\begin{tabular}{|c|c|c|c|c|}
\hline \multirow[t]{3}{*}{ Reason $^{a}$} & \multicolumn{4}{|c|}{ Abuse inflicted by } \\
\hline & \multicolumn{2}{|c|}{ Husband } & \multicolumn{2}{|c|}{ In-laws } \\
\hline & $\begin{array}{c}\text { Verbal } \\
\text { abuse } \\
(\%)\end{array}$ & $\begin{array}{l}\text { Physical } \\
\text { abuse } \\
(\%)\end{array}$ & $\begin{array}{c}\text { Verbal } \\
\text { abuse } \\
(\%)\end{array}$ & $\begin{array}{c}\text { Physical } \\
\text { abuse } \\
(\%)\end{array}$ \\
\hline Financial & 65.0 & 19.8 & 20.8 & 4.8 \\
\hline Infertility & 33.3 & 22.6 & 33.8 & 0.0 \\
\hline Not having a son & 32.0 & 18.8 & 28.5 & 19.3 \\
\hline Husband beating the children & 21.3 & 7.3 & 7.0 & 4.8 \\
\hline Husband's drug addiction & 15.8 & 15.8 & 0.0 & 20.5 \\
\hline Refusal of sex by wife & 4.8 & 1.8 & 0.0 & 0.0 \\
\hline Disobeying/arguing with in-laws & 4.8 & 38.8 & 2.5 & 7.5 \\
\hline Arguing with husband & 4.3 & 0.0 & 0.8 & 0.8 \\
\hline $\begin{array}{l}\text { Not understanding the household chores } \\
\text { needed or knowing how to do them }\end{array}$ & 3.0 & 0.5 & 4.5 & 1.3 \\
\hline Not doing the household chores properly & 2.5 & 3.0 & 80.3 & 28.8 \\
\hline Going out without permission & 2.3 & 0.5 & 2.3 & 0.0 \\
\hline Going to parent's home without permission & 2.0 & 0.0 & 3.3 & 0.0 \\
\hline Interference by wife's parents & 2.0 & 1.6 & 2.0 & 4.0 \\
\hline Conflicts about family planning & 1.3 & 1.0 & 0.5 & 0.0 \\
\hline Incitement by in-laws & 1.3 & 0.0 & 0.0 & 0.0 \\
\hline Husband taking another wife & 0.5 & 0.0 & 0.0 & 0.0 \\
\hline Dowry (too little or none) & 0.0 & 0.0 & 9.5 & 13.0 \\
\hline Exchange marriages (watta satta) ${ }^{b}$ & 0.0 & 0.0 & 2.8 & 0.0 \\
\hline Husband favouring wife over parents & 0.0 & 0.0 & 1.0 & 0.0 \\
\hline In-laws dislike wife & 0.0 & 0.0 & 3.8 & 0.0 \\
\hline Wife's extramarital affairs & 0.0 & 0.3 & 0.0 & 1.3 \\
\hline
\end{tabular}

$(80.3 \%)$, infertility $(33.8 \%)$, not having a son $(28.5 \%)$ and financial reasons $(20.8 \%)$ (Table 2).

\section{Reasons for physical violence from husband and in-laws}

The main reasons reported for physical violence by the husband included: disobeying and arguing with in-laws (38.8\%), infertil- ity $(22.8 \%)$, financial reasons $(19.8 \%)$, not having a son (18.8\%) and husband being addicted to drugs (15.8\%) (Table 2).

The main reasons reported for beating by in-laws included: household chores $(28.8 \%)$, husband addicted to drugs (20.5\%), not having a son (19.3\%), dowry issues (13.0\%), and disobeying and arguing with in-laws $(7.5 \%)$ (Table 2$)$. 


\section{Discussion}

Violence affects the lives of millions of women worldwide, of all socioeconomic and educational classes. However, a study conducted in medical clinics in Sudan in 2001 reported that women with low educational status and unemployed women and newly married women were more frequently abused [22]. Domestic violence cuts across cultural and religious barriers, undermining the right of women to participate fully in society [23].

Our community-based study found that the prevalence of conflict with the husband as perceived by the wife was about $98 \%$ and with in-laws about $97 \%$. The prevalence of physical abuse by husbands reported by the women was $80 \%$ and by the in-laws $58 \%$. Our findings support those of previous studies done in Egypt (34\%) [5], Canada (17\%) [6], Haiti (16.4\%) [7], Bangladesh (42\%) [24], India (30\%) and some squatter settlements of Pakistan (34\%) [8,16-18], but our figures are much higher. The high prevalence of perceived violence against women in this study could be attributed to the fact that $50 \%$ of our participants were either not educated or had had only limited schooling. It has been reported generally that a woman's ability to make decisions is acquired when she has had at least 10 years of schooling [7]. As reported by one study, many women perceived that education improved women's status and increased their contribution to their households, thereby awarding them more freedom and less dependency [24]. In the women's view, education has both a direct effect on women's status and an indirect effect that operates through increased earning potential. On the other hand, the study identified that a husband's violence against his wife was associated with the woman being more financially independent. This indicates that a shift in the balance of power between husband and wife can lead to violence.

A predisposing factor for our participant's perception of domestic violence is the power bestowed upon males which subjugates women and makes them submissive to men. In Pakistan, the bride generally lives with her in-laws and looks upon them as the ultimate authority figure in the household. This gives power to the in-laws. The bride's parents are not supposed to interfere with the life of their daughter once she is married. Any attempt on the part of the bride's parents to influence her may lead to conflicts with the husband and the in-laws. It may even go as far as the husband and inlaws beating the wife to show their power.

Financial issues were an important reason for domestic violence in our study. This finding has been reported by many other studies. For example, studies on Haitian and Native American women showed that because of their lack of financial contribution they perceived themselves as powerless $[7,8]$. In Pakistan, a number of NGOs are working to raise the economic status of women by offering them microcredit. However, these programmes are providing protection only to a very few because many women are not aware of the schemes or may not be allowed by the husband/the family to go to a bank or NGO to learn about the system.

Infertility and not giving birth to a son were 2 other reasons for violence found in our study. In the communities studied, it is believed that the woman alone is responsible for the sex of a child. The concept of male involvement in providing $\mathrm{X}$ and $\mathrm{Y}$ chromosomes to the female is either unknown, unclear or completely ignored. In addition, such families are not aware of how much the male can contribute to the cause of infertility. It is the woman who is held responsible for infertility, becomes so-

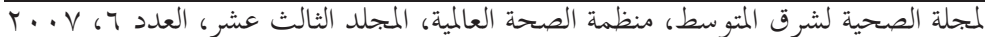


cially stigmatized and possibly the victim of verbal and physical abuse too [20]. In China and India, some women choose to terminate their pregnancies when expecting daughters but carry their pregnancies to term when expecting sons $[25,26]$. Further an Egyptian study identified that women are not aware of their reproductive rights [27].

Another perceived reason for the abuse suffered by our participants was the drug addiction of the husband. Other studies have reported on the association between domestic violence and drug and alcohol use $[25,28]$.

Domestic chores are one of the reasons reported by women in our study particularly in relation to the in-laws. The wife will work for 24 hours without recognition and rest because little social value is given to her by her husband and in-laws. This may result in the woman becoming stressed and irritable which then often gives the husband and in-laws the opportunity to physically abuse her. Many men and in-laws have false socioreligious belief that women have lower intellects than men and are thus not able to understand what is right for them and make proper decisions. Therefore, they are overprotective of the woman and completely limit her mobility and contact with others [16]. In addition in our culture women's exposure to men other than the husband tends to be restricted. The women in our study reported that their husbands were jealous if they talked to other men. This result is supported by the qualitative study we conducted to develop the questionnaire that found that when women talk to another man, it is viewed almost as an extramarital affair.

The major limitation in this study was the non-random purposive sampling technique used whereby only women of low socioeconomic level were recruited. This was done because domestic violence in our culture is a very sensitive issue and people tend not to wish to discuss it especially with strangers. Therefore, the health care workers were used to collect the data as they were known to the women and her family and had a rapport with them. We collected information only about physical (beating), and verbal (conflict) violence. Due to the sensitivity of the topic, we did not collect information on sexual violence, which is another limitation of our study. The findings of this study should be taken in the light of these limitations. Despite this, we believe the study contributes to our understanding of the prevalence of and possible reasons for domestic violence among urban women of low socioeconomic status in Karachi, Pakistan.

We conclude that the prevalence of domestic violence among such women is high and this violence puts the women under considerable stress. The main reported reasons for the violence are public health issues which should be addressed by health professionals. There is therefore a need for women's empowerment through increased schooling and improved financial capacity so that they are able to participate in the decision-making process of a household. The media could play a leading role in persuading society to be more supportive of women and their role in society. Awareness is the first step towards a more supportive and tolerant society.

\section{Acknowledgements}

We would like to thank the Aga Khan University, Karachi, Pakistan for providing the grant for conducting this study. We would also like thank all the participants and staff of this project without whose help the study would not have been possible. In addition, we would like to thank Dr Sanah Baig for editing the paper. Finally, we thank Dr Neelofar Sami, the principal investigator of the larger project. 


\section{References}

1. Heise L, Pitanguy J, Germain A. Violence against women: The hidden health burden. Washington DC, The World Bank, 1994.

2. Flitcraft A et al. Diagnostic and treatment guidelines on domestic violence. Chicago, American Medical Association. 1992

3. Violence against women. WHO consultation, Geneva, 5-7 February, 1996. Geneva, World Health Organization, 1996 (FRH/WHD/96.27)

4. Sexual violence. In: Krug EG et al., eds. World report on violence and health. Geneva, World Health Organization, 2002:147-82.

5. Sidibe ND, Campbell JC, Becker S. Domestic violence against women in Egyptwife beating and health outcomes. Social science \& medicine, 2006, 62:1260-77.

6. Cohen MM et al. Intimate partner violence among Canadian women with activity limitations. Journal of epidemiology and community health, 2005, 59:834-9.

7. Gage AJ. Women's experience of intimate partner violence in Haiti. Social science \& medicine, 2005, 61:343-64.

8. Harwell TS, Moore KR, Spence MR. Physical violence, intimate partner violence, and emotional abuse among adult American Indian men and women in Montana. Preventive medicine, 2003 , 37(4):297-303.

9. Haji-Yahia MM. The incidence of wife abuse and battering and some sociodemographic correlates as revealed by two national surveys in Palestinian society. Journal of family violence, 2000 , 14(4):347-74.

10. Michau L, Naker D. Mobilizing communities to prevent domestic violence. A resource guide for organizations in East and Southern Africa. Kampala, Uganda, Raising Voices, 2003.
11. Cohen $\mathrm{M}$ et al. Domestic violence and childhood sexual abuse in HIV-infected women and women at risk for HIV. American journal of public health, 2000, 90(4):560-5.

12. Campbell JC. Health consequences of intimate partner violence. Lancet, 2002 , 359(9314):1331-6.

13. Karol RL, Micka RG, Kuskowski M. Physical, emotional, and sexual abuse among pain patients and health care providers: Implications for psychologists in multidisciplinary pain treatment centers. Professional psychology: research and practice, 1992, 23(6):480-5.

14. Nduna S, Goodyear L. Pain too deep for tears: Assessing the prevalence of sexual and gender violence among Burundian refugees in Tanzania. New York, International Rescue Committee, 1997.

15. Bustamante-Gavino MI. The effects of the Nurse Program on the self esteem of Filipino abused women [Doctoral thesis]. Manila, University of the Philippines, 1998.

16. Shaikh MA. Domestic violence against women-perspective from Pakistan. Journal of the Pakistan Medical Association, 2000, 50(9):312-4.

17. Fikree FF, Bhatti LI. Domestic violence and health of Pakistani women. International journal of gynaecology and obstetrics, 1999, 65(2):195-201.

18. Fikree FF, Razzak JA, Durocher J. Attitude of Pakistani men to domestic violence: a study from Karachi Pakistan. Journal of men's health and gender, 2005 , 2(1):40-58.

19. Sami N, Ali TS. Psycho-social consequences of secondary infertility in Karachi. Journal of the Pakistan Medical Association, 2006, 56(1)19-22.

المجلة الصحية لشرق المتو سط، منظمة الصحة العالمية، المجلد الثالث عشر، العدد ب، V... 
20. Irfan N, Badar A. Top ten stressors in the hysterical subjects of Peshawar. Journal of Ayub Medical College Abbottabad, 2002, 14(4):38-41.

21. Alvarez-Dardet C, Ashton JR. Practising public health beyond medicine. Journal of epidemiology and community health, 2004, 58:533.

22. Ahmed AM, Elmardi AE. A study of domestic violence among women attending a medical centre in Sudan. Eastern Mediterranean health journal, 2005, 11(12):164-74.

23. Watts C, Zimmerman C. Violence against women: global scope and magnitude. Lancet, 2002, 359:1232-7.

24. Bates LM et al. Socioeconomic factors and processes associated with domestic violence in rural Bangladesh. International family planning perspectives, 2004, 30(4):190-9.
25. Parish WL et al. Intimate partner violence in China: national prevalence, risk factors and associated health problems. International family planning perspectives, 2004, 30(4):174-81.

26. Bandyopadhyay M. Missing girls and son preference in rural India: looking beyond popular myth. Health care women international, 2003, 24(10):910-26.

27. Abou Shabana K et al. Women's perceptions and practices regarding their rights to reproductive health. Eastern Mediterranean health journal, 2003, 9(3):296-308.

28. Cunradi CB, Raul C, John S. Alcoholrelated problems, drug use, and male intimate partner violence severity among US couples: Alcoholism. Alcoholism, clinical and experimental research, 2002, 26(4):493-500.

\section{Violence and injury prevention: road traffic injuries}

http://www.emro. who.int/vip/roadtrafficinjuries-regionaldata.htm

In 2002 there were an estimated 132207 road traffic deaths in the WHO Eastern Mediterranean Region (362 deaths/day).

The Region has the highest rate of road traffic deaths among males. In low- and middle-income countries, the annual road traffic death rate for males (117.0/100 000) is more than double the rate for low- and middle-income countries across the world (53.3/100 000). For males aged 45-59, the rate in low- and middle-income countries in the Region (63.9/100 000) is 50\% higher than that in low- and middleincome countries across the world (43.2/100 000).

Similarly, the annual road traffic death rate for females aged 60 and over in the Eastern Mediterranean Region as a whole (46.0/100 000) is $241 \%$ higher than the rate for females in this age group across the world (19.1/100 000). 